\title{
Imitation and social facilitation in the pigeon
}

\author{
THOMAS R. ZENTALL and DAVID E. HOGAN \\ University of Kentucky, Lexington, Kentucky 40506
}

\begin{abstract}
The sight of another pigeon pecking a response key for grain resulted in similar pecking by more pigeons than did the sight of another pigeon eating or the sight of another pigeon (neither pecking nor eating). But more pigeons pecked the response key when they could see another pigeon that was neither pecking nor eating than when no other pigeon was there (whether or not key-light/grain pairings were observable in the adjacent compartment). Finally, observation of another pigeon pecking but not eating produced pecking comparable to observation of both pecking and eating. The presence of both imitation and social facilitation of keypecking were demonstrated. Observation of the consummatory response contributed little to keypecking.
\end{abstract}

The present study demonstrated imitative behavior of a positively reinforced response in the pigeon while ruling out or assessing the contribution of simple social factors.

Imitation can be described as the tendency to match behavior, and is analogous to stimulus matching in a matching-to-sample task (Gerwirtz, 1969), but imitation is difficult to define operationally except by the exclusion of other social factors. The presence of a conspecific may "draw attention" to a relevant stimulus. For example, a bird would be more likely to discover a feeder if there were another bird (a salient stimulus) eating from the feeder. The attention-getting function of a performing conspecific has been referred to as local enhancement (Klopfer, 1959). Local enhancement effects can be reduced or eliminated by separating the location of the demonstrator's response from that of the observer. Thus, should the observer orient towards the demonstrator, the observer would be orienting away from its own manipulandum.

The presence of a conspecific (independent of its behavior) can also produce motivational changes, often referred to as social facilitation, that can increase or decrease performance, depending on whether the change in motivation produces a behavioral change compatible or incompatible with learned or to-be-learned behavior (Zajonc, 1965). Motivational effects produced by the presence of a conspecific cannot be prevented, but they can be assessed by exposing control animals to conspecifics not performing the response in question. If the term "imitation" is to have more than descriptive value, then it must be distinguished from behavioral changes due to other factors.

Imitation in rats has been found when the observed

Supported in part by NIMH grants 19757 and 24092 to T.R.Z. Requests for reprints should be sent to Thomas R. Zentall, Department of Psychology, University of Kentucky, Lexington, Kentucky 40506. behavior has been negatively reinforced or punished. Kohn (1976) and Kohn and Dennis (1972) have reported faster acquisition of a discriminated avoidance task when rats could observe a conspecific performing the discrimination (observer's $S+$ and $\mathrm{S}$ - were the same as demonstrator's $\mathrm{S}+$ and $\mathrm{S}-$ ) than when they could observe performance of the reversal (demonstrator's $S$ - becomes observer's $S+$ and demonstrator's $\mathrm{S}+$ became observer's $\mathrm{S}-$ ). Similarly, Lore, Blanc, and Suedfeld (1971) found that punished approach responses to a lighted candle decreased if rats had observed a conspecific getting burned earlier, but not after observing a conspecific trying unsuccessfully to approach the candle. Imitation has also been found in rats under conditions of positive reinforcement. Zentall and Levine (1972) have reported faster acquisition of a barpress response while observing a barpressing conspecific than while observing an experimentally naive conspecific, or no conspecific.

The only report of imitation in birds has been by Klopfer (1957), who exposed ducks to conspecifics trained to avoid food placed on a distinctively colored background, and found that the observers would also avoid food placed on that background, even when the demonstrators were no longer present. The present study examined imitation of a positively reinforced response in the pigeon to assess the generality of such learning under conditions that minimized the effects of local enhancement and allowed for the separate assessment of socialmotivational effects.

\section{METHOD}

\section{Subjects}

Sixty-eight experimentally naive loft-reared pigeons were reduced to $75 \%-80 \%$ of their free-feeding weights.

\footnotetext{
Apparatus

Three experimental sound-attenuated chambers contained two compartments (each $33 \mathrm{~cm}$ high, $28 \mathrm{~cm}$ wide, and $17 \mathrm{~cm}$ deep) separated by a piece of Plexiglas $(33 \mathrm{~cm}$ high and $28 \mathrm{~cm}$ wide).
} 
On the front wall of each compartment was a panel, on which a rear-mounted grain feeder was centrally located. Above the feeder was a translucent response key $(2.5 \mathrm{~cm}$ diam) that could be transilluminated from the rear. Above the response key was a 2.8-W lamp that was illuminated continuously. The front-wall panels were located such that when a pigeon was placed in each compartment facing the panel, the two pigeons were side by side facing the same direction.

\section{Procedure}

All birds were trained to eat from the grain feeder when it was raised. Six birds were trained as demonstrators: Two birds (keypeck demonstrators) were trained to peck the response key, which raised the grain feeder. They were then exposed to a discretetrial, fixed-interval schedule of reinforcement, i.e., the first response that occurred $9 \mathrm{sec}$ after the key was lit raised the grain feeder for $3 \mathrm{sec}$ and darkened the key. The key remained dark between trials for a variable duration averaging $30 \mathrm{sec}$. Two other birds (consummatory demonstrators) were exposed to the same number of grain feeder presentations as the keypeck demonstrators by simultaneously operating the grain feeders in the keypeck demonstrators' and the consummatory demonstrators' chambers. For the consummatory demonstrators, the response key remained dark and pecks were ineffective. Two other birds (naive demonstrators) were exposed to the chambers for the same amount of time as the other demonstrators but experienced neither the lighted key nor the raised grain feeder.

Fifty of the remaining birds (observers) served as subjects and were equally divided into five groups distinguished by the conditions of observation. Keypeck observers (KPO) were exposed to a keypeck demonstrator in the adjacent compartment. Naive observers (NO), exposed to a naive demonstrator in the adjacent compartment, served as a control for the mere presence of a conspecific. Consummatory observers $(\mathrm{CO})$, exposed to a consummatory demonstrator in the adjacent compartment, served as a control for the additional motivational effects produced by the presence of a conspecific that was eating. Empty compartment observers (EO), exposed to an empty compartment, served as a control for the absence of events in the adjacent compartment. Information observers (IO), exposed to key light and raised grain feeder in the empty adjacent compartment, served as a control for keypecks resulting from secondary conditioning. The temporal pairings of key light with grain typically produces keypecking by pigeons (Brown \& Jenkins, 1968), even when the grain is inaccessible, as it would be if observed from an adjacent compartment (Zentall \& Hogan, 1975). This represents a secondary conditioning procedure, because the key light is paired with cues associated with grain (e.g., sight of grain and sound of grain feeder) rather than with the consumption of grain.

All observing birds were exposed to the same sequence of events in their own compartments: 50 key light presentations, about $8 \mathrm{sec}$ each (determined by the duration of key light for the keypeck observers), separated by variable intertrial intervals (30 sec on the average), during which the key was dark. For 7 of the 10 birds in each group, each peck to the lighted key produced $3 \mathrm{sec}$ access to mixed grain (continuous reinforcement). For the remaining 3 birds in each group, pecks did not produce grain (extinction). The observer birds were run in squads of 5 , each squad containing 1 bird from each group. Two squads were run each day.

The remaining 12 birds were assigned to Groups KPO, NO, and EO (4 birds to each group). For these observers, pecks to the lighted key were reinforced on a variable interval 20 -sec schedule of reinforcement. These birds were included in the study to test whether a schedule of reinforcement less dense than continuous reinforcement but more dense than extinction might be more sensitive to social and imitational effects once pecking began. In all other respects, they were treated as were the other birds in their respective groups.

\section{RESULTS AND DISCUSSION}

Table 1 shows the number of birds in each observer group that pecked the response key, the median trial of the first peck (given a peck), and the median number of pecks for (1) observers reinforced continuously, (2) observers reinforced on a variable interval 20-sec schedule, and (3) observers not reinforced for pecking.

Proportionally more birds pecked in the imitation group, KPO (11 of 14), than in the social facilitation control groups, $\mathrm{CO}$ and NO (8 of 24), $p=.009 .{ }^{1}$

The mere presence of a conspecific (Group NO), however, facilitated keypecking relative to the absence of a conspecific (Groups EO and IO), with 5 of 14 vs. 2 of 24 birds pecking, respectively, $\mathrm{p}=.050$.

The sight of a bird eating did not facilitate keypecking more than the mere presence of another bird

Table 1

Performance of Pigeons Exposed to a Keypecking Demonstrator (KPO), an Eating Demonstrator (CO), a Merely Presently Demonstrator (NO), an Empty Compartment (EO), or an Empty Compartment with Keylight/Grain Pairings (IO)

\begin{tabular}{|c|c|c|c|c|c|}
\hline & \multicolumn{5}{|c|}{ Condition } \\
\hline & KPO & $\mathrm{CO}$ & NO & EO & 10 \\
\hline Number of birds in each condition & 14 & 10 & 14 & 14 & 10 \\
\hline Number of birds pecking & 11 & 3 & 5 & 1 & 1 \\
\hline \multicolumn{6}{|l|}{ Trial of first peck } \\
\hline median* & 10 & 7 & 16 & 12 & 26 \\
\hline range & $3-41$ & $1-8$ & $2-35$ & & \\
\hline \multicolumn{6}{|l|}{ Total pecks reinforced continuously } \\
\hline median & $57.5(6) \dagger$ & $85(2)$ & $25(3)$ & $73(1)$ & \\
\hline range & $4-111$ & $1-130$ & $1-29$ & & \\
\hline \multicolumn{6}{|l|}{ Total pecks reinforced, VI $20 \mathrm{sec}$} \\
\hline median & $157(3)$ & & $7(1)$ & & \\
\hline range & $133-208$ & & & & \\
\hline \multicolumn{6}{|l|}{ Total pecks nonreinforced } \\
\hline median & $1(2)$ & 1(1) & $7(1)$ & & $4(1)$ \\
\hline
\end{tabular}

*Given at least one peck.

†Numbers in parenthesis refer to number of birds pecking out of seven reinforced continuously for pecking, four reinforced on a variable-interval 20 -sec schedule, and three nonreinforced for pecking. 
(Group CO vs. Group NO), with 3 of 10 and 5 of 14 birds pecking, respectively; and the pairing of key light with the sight of grain in the empty adjacent compartment did not facilitate keypecking more than the sight of the empty adjacent compartment without the key-light/grain pairings (Group IO vs. Group EO), with 1 of 10 and 1 of 14 birds pecking, respectively.

Median trials to the first peck, and median number of pecks (given at least one peck) did not differ systematically across groups within each of the reinforcement conditions, except for the VI 20-sec schedule. However, the small number of birds that pecked at least once under this schedule of reinforcement makes meaningful comparison of number of pecks questionable. Number of pecks may not show the effects of imitation, because some of the observers that would not have pecked while observing the mere presence of a conspecific but were facilitated by watching a keypecking bird may have been birds that pecked late in the session (see range of trials to first peck).

All birds were subsequently exposed to a second session of 50 key-light presentations, identical to the first session. A total of seven birds that had not pecked the response key during the first session did so during the second session: one each from Groups KPO, CO, and IO and two each from Groups NO and EO. The small number of pecks made by birds that were not reinforced for pecking indicates that observation of pecking tends to initiate, but cannot maintain, pecking by the observer.

That more birds in Group IO did not peck suggests that key-light/grain pairings do not play a role in imitative behavior. An alternative means of assessing the role of key-light/grain pairings is to omit the pairings of key light and grain rather than to omit the demonstrator.

Twenty-four birds, selected from among those which had not pecked the response key were randomly assigned to three groups. Each bird in Group KPO2 (10 birds) was treated exactly as were birds in Group KPO. Each bird in Group KPNCO (10 birds) was exposed to a demonstrator that was pecking the response key but was not being reinforced. Thus, Group KPNCO observed the keypeck but not the consummatory response. To insure that the nonreinforced demonstrators would not stop keypecking during experimental sessions, they were pretrained with key-light presentations that could be followed by grain with a probability of .25 . Each of these demonstrators was also exposed to such a retraining session at the end of each experimental session, with a "dummy" bird in the adjacent compartment. Each bird in Group NO2 (4 birds) was treated exactly as were birds in Group NO. During experimental sessions, all observer pecks were reinforced. All groups received two experimental sessions of $50 \mathrm{key}-$ light presentations.

During the first experimental session, four KPO2 birds, three KPNCO birds, and no NO2 birds pecked the response key. During both sessions, a total of eight KPO2 birds, six KPNCO birds, and no NO2 birds pecked the response key. ${ }^{2}$ Again, trials to the first peck, given a peck, and total pecks varied greatly. Comparison of Group KPO2 with Group KPNCO suggests that little of the facilitation shown by Group KPO could have been due to keylight/grain pairings.

The presence of a keypecking bird (Groups KPO2 and KPNCO) facilitated keypecking relative to the mere presence of a bird (Group NO2), with 14 of 20 vs. 0 of 4 birds pecking, respectively, $p=.020$. Thus, the results of the second experiment confirm the imitation effect found in the first experiment.

The present results suggest the capacity for imitation learning in the pigeon, though one could argue that the presence of a pecking conspecific functions as a "releaser" (Tinbergen, 1951) of pecking by pigeons (the distinction being between imitation learning, involving the acquisition of a new response, and imitation performance, involving the performance of an "innate" or already learned response). Pecking is clearly a well-established response for the pigeon, but since the observing pigeons had had no prior experience pecking at lighted response keys, learning was probably also involved. Also, if pecking by a pigeon "releases" pecking by an observing pigeon, it is not clear why the pecks should be directed at the response key, rather than at the light above the response key, at the floor, or at screw heads on the front panel. Experimenter observation of the pigeons prior to the first keypeck indicated the occurrence of partial pecks to the response key (insufficient to operate the microswitch), but there was no evidence of pecking at other objects in the compartment. One could rule out the releaser explanation entirely if one trained demonstrators to peck at different locations in the compartment and found that observing pigeons tended to match the location of the demonstrator's peck.

The results of the present experiment differ somewhat from findings with rats that have shown that observing the mere presence of a conspecific results in retarded learning relative to observing an empty compartment (Zentall \& Levine, 1972). The different outcomes may indicate important species differences in the effects of conspecifics on learning, though it is possible that differences in the nature of the response (pecking for pigeons; barpressing for rats) 
were also responsible. For the pigeon, pecking is a response closer in topography to consummatory behavior than is barpressing for the rat.

\section{REFERENCES}

Brown, P. L., \& Jenkins, H. M. Auto-shaping of the pigeon's key-peck. Journal of the Experimental Analysis of Behavior, $1968,11,1-8$.

GERWITZ, J. L. Mechanisms of social learning. In D. A. Goslin (Ed.), Handbook of socialization theory and research, Chicago: Rand McNally, 1969.

KIOPFER, P. H. Empathetic learning in ducks. American Naturalist, 1957, 91, 61-63.

KLOPFER, P. H. Social interactions in discrimination learning with special reference to feeding behavior in birds. Behavior, 1959 , 14, 282-299.

KонN, B. Observation and discrimination learning in the rat: Effects of stimulus substitution. Learning and Motivation, 1976, 7, 303-312.

Koнn, B., \& Dennis, M. Observation and discrimination learning in the rat: Specific and nonspecific effects. Joumal of Comparative and Physiological Psychology, 1972, 78, 292-296.

LoRe, R., Blanc, A., \& Suedfeld, P. Empathetic learning of a passive avoidance response in domesticated Rattus norvegicus. Animal Behaviour, 1971, 19, 112-114.
Tinbergen, N. The study of instinct. Oxford: Clarendon Press, 1951.

Walker, H. M., \& Lev, J. Statistical inference. New York: Holt. Rinehart, \& Winston, 1953.

Zajonc, R. B. Social facilitation. Science, 1965, 149, 269-274.

Zentall, T. R., \& Hogan, D. E. Key pecking in pigeons produced by pairing key light with inaccessible grain. Journal of the Experimental Analysis of Behavior, 1975, 23, 199-206.

Zentall, T. R., \& Levine, J. M. Observational learning and social facilitation in the rat. Science, 1972, 178, 1220-1221.

\section{NOTES}

1. The $p$ values reported refer to exact probabilities of the chance occurrence of such outcomes, or outcomes more deviant, given the observed marginal frequencies (see, for example, Walker \& Lev, 1953).

2. One might argue that some of the keypecking by Group KPNCO was produced by birds that had previously observed a consummatory demonstrator; however, there were only two birds from Group $\mathrm{CO}$ in the second experiment, only one of which was in Group KPNCO, and that bird failed to peck.

(Received for publication January 12, 1976; revision accepted July 23,1976 .) 